\title{
Respiratory coinfections in COVID-19 patients evaluated by BioFire Pneumonia Panel
}

\author{
Hebatallah Hany Assal ${ }^{1 *}$ D, Maged Salah², Ayman Kamal Ibrahim³ ${ }^{3}$, Mostafa Alfishawy ${ }^{4}$, Rawia Khater ${ }^{5}$, \\ Hossam Hosny Masoud', Ahmed Monier Eldemerdash ${ }^{6}$ and Mohamed Ali AbdelHalim²
}

\begin{abstract}
Background: Routine administration of antibacterials in patients with Covid-19 has been a subject of debate, with no solid data about the true prevalence of respiratory coinfections in Covid-19 patients in different geographic areas. The aim of the current study was to identify respiratory coinfections in Covid-19 patients admitted to the hospital and to identify its genetic resistance pattern using the respiratory multiplex polymerase chain reaction (PCR).

Results: The study included 40 patients, 32 males (80\%) and 8 (20\%) females with a mean age of $59.3 \pm 12.6$. Half of the patients had respiratory bacterial coinfections documented by pneumonia (PN) panel. The most common isolate was Klebsiella pneumoniae (10/20,50\%), followed by Acinetobacter calcoaceticus baumanni complex (7/20, $35 \%)$. Regarding genetic resistance, thirteen (13/20,65\%) isolates were proven extended spectrum beta lactamase (ESBL)-producing Enterobacteriaceae. Thirteen (13/20,65\%) isolates were proven carbapenemase-producing organisms testing positive for New Delhi metallo- $\beta$-lactamase (NDM), oxacillinase $\beta$-lactamases (OXA-48), and Verona Integron-Encoded Metallo- $\beta$-Lactamase (VIM) (7/20, 35\%; 5/20, 25\%; 1/20, 5\%, respectively). The four isolated Staphylococcus aureus were methicillin-resistant (4/20, 20\%).

Conclusion: In our cohort, there was 50\% rate of bacterial respiratory coinfection in patients with severe Covid-19 admitted to the ICU with high rates of carbapenemase-producing gram-negative bacteria that required escalation of antibacterials and represented a challenge to clinicians.
\end{abstract}

Keywords: COVID-19, SARS-CoV-2, Klebsiella pneumoniae, Acinetobacter calcoaceticus baumanni complex, BioFire FilmArray Pneumonia Panel

\section{Background}

Health care systems worldwide have been facing a real challenge with coronavirus disease 2019 (Covid-19) caused by severe acute respiratory syndrome coronavirus 2 (SARS-COV-2) with its rapid spread all over the globe. As of December 5, 2020, more than 66 million cases of Covid-19 have been reported globally, with more than 1.5 million deaths [1].

\footnotetext{
* Correspondence: Hebatallah.Assal@kasralainy.edu.eg

${ }^{1}$ Department of Chest Medicine, Faculty of Medicine, Cairo University, Al Kasr Al Aini, Old Cairo, Cairo 11956, Egypt

Full list of author information is available at the end of the article
}

Inflammatory markers that are usually associated with bacterial infections as C-reactive protein (CRP) have been shown to be elevated in severe Covid-19 regardless of presence of bacterial coinfection [2].

The severity of presentation of critically ill patients and lack of specific antivirals together with difficulty of clinical or radiological ruling out of secondary bacterial infections had put clinicians worldwide in a great challenge [3].

Published reports using national health care associated infections surveillance data points to a high burden of multi-drug-resistant (MDR) pathogens in Egyptian

\section{Springer Open}

(c) The Author(s). 2021 Open Access This article is licensed under a Creative Commons Attribution 4.0 International License, which permits use, sharing, adaptation, distribution and reproduction in any medium or format, as long as you give appropriate credit to the original author(s) and the source, provide a link to the Creative Commons licence, and indicate if changes were made. The images or other third party material in this article are included in the article's Creative Commons licence, unless indicated otherwise in a credit line to the material. If material is not included in the article's Creative Commons licence and your intended use is not permitted by statutory regulation or exceeds the permitted use, you will need to obtain permission directly from the copyright holder. To view a copy of this licence, visit http://creativecommons.org/licenses/by/4.0/. 
health care facilities [4]. This had led to adopting the strategy of early initiation of empirical broad-spectrum antimicrobials covering MDR gram-positive and gramnegative pathogens.

Therefore, rapid pathogen detection and susceptibility profile determination are crucial. As timely action with tailored appropriate antimicrobial therapy is of extreme importance for decreasing the load on health care facilities and better clinical outcomes.

Routine diagnostic methods including culture-based pathogen detection and antimicrobial susceptibility testing have several limitations. The delayed results, in addition to the false-negative results called for the need for more rapid, sensitive, and reliable techniques for bacterial identification.

The BioFire FilmArray ${ }^{\circ}$ Pneumonia (PN) Panel has recently been incorporated into clinical practice as a rapid and sensitive method for identifying number of typical and atypical bacterial pathogens, respiratory viruses, and several classes of antimicrobial susceptibility-associated genes directly from sputum, endotracheal aspirate
(ETA), and bronchoalveolar lavage-like specimens in approximately $1 \mathrm{~h}$ (Table 1 ). The assay provides semiquantitative results for 15 typical respiratory bacterial pathogens [5].

The aim of the current study was to identify respiratory co infections in Covid-19 patients admitted to the hospital and to identify its genetic resistance pattern using the BioFire FilmArray method.

Furthermore, to identify the relationship of respiratory coinfections with the demographic characteristics of Covid-19 patients as well as the severity of the disease, length of hospital stay, and final outcome.

\section{Methods}

A single-center retrospective study was done from March 2020 till October 2020. It included all adult ( $>18$ years) patients admitted to Covid-19 ICU in Misr International Hospital (Cairo, Egypt) for acute respiratory failure related to SARS-COV-2 (RT-PCR positive for SARS-COV-2 on a nasopharyngeal swab) pneumonia. Upon admission, patients were encouraged to obtain a

Table 1 FilmArray Pneumonia Panel plus targets

\begin{tabular}{|c|c|}
\hline Category & Target \\
\hline Typical bacteria & $\begin{array}{l}\text { Acinetobacter calcoaceticus-baumannii complex } \\
\text { Enterobacter cloacae complex } \\
\text { Escherichia coli } \\
\text { Haemophilus influenzae } \\
\text { Klebsiella aerogenes } \\
\text { Klebsiella oxytoca } \\
\text { Klebsiella pneumoniae group } \\
\text { Moraxella catarrhalis } \\
\text { Proteus spp. } \\
\text { Pseudomonas aeruginosa } \\
\text { Serratia marcescens } \\
\text { Staphylococcus aureus } \\
\text { Streptococcus agalactiae } \\
\text { Streptococcus pneumoniae } \\
\text { Streptococcus pyogenes }\end{array}$ \\
\hline Atypical bacteria & $\begin{array}{l}\text { Chlamydia pneumoniae } \\
\text { Legionella pneumophilia } \\
\text { Mycoplasma pneumoniae }\end{array}$ \\
\hline Viruses & $\begin{array}{l}\text { Adenovirus } \\
\text { Coronavirus } \\
\text { Human metapneumovirus } \\
\text { Human rhinovirus/enterovirus } \\
\text { Influenza A } \\
\text { Influenza B } \\
\text { Middle East respiratory syndrome coronavirus (MERS-CoV) } \\
\text { Parainfluenza virus } \\
\text { Respiratory syncitial virus }\end{array}$ \\
\hline Antimicrobial resistance genes & $\begin{array}{l}\text { Extended spectrum } \beta \text {-lactamase-producing Enterobacteriaceae } \\
\text { CTX-M } \\
\text { Carbapenemase-producing organisms } \\
\text { NDM } \\
\text { OXA-48-like } \\
\text { VIM } \\
\text { IMP } \\
\text { KPC } \\
\text { Methicillin-resistant Staphylococcus aureus } \\
\text { mecA/C and MREJ }\end{array}$ \\
\hline
\end{tabular}


sputum sample for analysis. Tracheal aspirate was obtained from intubated patients. Patients that were not able to obtain a sputum sample as well as patients that had a negative RT-PCR for SARS-COV-2 on a nasopharyngeal swab were excluded from the study.

Conscious patients were given sterile cups and were encouraged to collect their respiratory secretions for microbiological sampling. Respiratory samples that were collected were sent to the microbiology laboratory where a BioFire FilmArray Pneumonia Panel was performed.

The BioFire FilmArray Pneumonia Panel (PN panel; BioFire Diagnostics, LLC) is a multiplex PCR-based diagnostic test that analyzes respiratory samples (sputum, endotracheal aspirates, bronchoalveolar lavage) and specimens for the presence of bacteria, viruses, and genetic markers of antimicrobial resistance within approximately $75 \mathrm{~min}$.

It is a closed system disposable that keeps all the necessary reagents for sample preparation, reverse transcription, polymerase chain reaction (PCR), and detection in order to isolate, amplify and detect nucleic acid from multiple lower respiratory pathogens within a single respiratory specimen.

After sample collection, the user injects hydration solution and $200 \mu \mathrm{L}$ of respiratory specimen sample combined with sample buffer into the pouch, places the pouch onto a FilmArray instrument, and starts a run. The entire run process takes about $1 \mathrm{~h}$, the system also uses real-time amplification data from the assays relative to a Quantified Standard Material (QSM) included in the pouch to provide an estimated value in genomic copies per milliliter (copies $/ \mathrm{ml}$ ) for bacterial analytes.

The PN panel reports qualitative ("detected" or "not detected") results for viral targets, bacterial targets associated with atypical pneumonia, and antibiotic resistance markers while providing a semiquantitative value for 15 additional bacterial targets commonly associated with respiratory infections (Table 1) [6].

Recently published studies investigated the agreement of semiquantitative results of the BioFire FilmArray ${ }^{\circ}$ Pneumonia Panel test with the routine culture by comparing semiquantitative results of the PN panel (which is the number of genomic copies per milliliter) and quantitative culture (which is the colony forming unit per milliliter). The results of the studies revealed that samples that showed $\geq 10^{5}$ copies $/ \mathrm{ml}$ of bacterial nucleic acids using the PN panel when cultured by conventional methods revealed significant amounts in culture.

Hence, in our study, samples showing semiquantitative results of $\geq 10^{5}$ genomic copies $/ \mathrm{ml}$ were included in the study and were considered true infection $[5,6]$.

One hundred Covid-19 patients were admitted to our ICU. Thirty-seven of them were able to obtain a sputum sample. Bronchoscopy and bronchoalveolar lavage were done in two patients, tracheal aspirate was obtained in one patient. Blood investigations as well as results of PN panel were retrospectively reviewed.

Data collected from patients' records were age, gender, length of hospital stay, comorbidities, mechanical ventilation, days on mechanical ventilation, type of respiratory sample, results of BioFire test, total leukocytic count, D-dimer, ferritin, C-reactive protein, absolute lymphocytic count, medication sheet, and outcome of patients.

All our patients were treated with an empiric antibiotic therapy covering methicillin-resistant Staphylococcus aureus (MRSA) and extended spectrum beta lactamase (ESBL) producing Gram-negative bacteria. Escalation was performed when indicated by adding colistin and increasing dose of meropenem (extended release) if a carbapenem resistant pathogen was encountered.

All patients received methylprednisolone $1-2 \mathrm{mg} / \mathrm{kg} /$ day as well as prophylactic anticoagulation. Patients with increasing inflammatory markers (ferritin, D-dimer, and CRP) and with increasing oxygen requirements with clinical signs of deterioration were given tocilizumab 8 $\mathrm{mg} / \mathrm{kg}$ for maximum 2 doses $24 \mathrm{~h}$ apart.

The study protocol was approved by the institutional review board of Ministry of Health, Cairo, Egypt (No: 32021/19).

\section{Statistical analysis}

Data was encoded and entered by using the statistical package SPSS version 21. The data were summarized by using number and percentage for qualitative variables, mean and standard deviation for normally distributed quantitative variable, and median and interquartile range for quantitative variables which are not normally distributed. Comparison between groups was done using chisquare test for qualitative variable while independent sample t-test was used for quantitative variable which are normally distributed. Non-parametrical MannWhitney test was used for quantitative variables which are not normally distributed. $\mathrm{P}$ value less than or equal to 0.05 were considered as statistically significant.

\section{Results}

The study included 40 patients, $32(80 \%)$ males and 8 (20\%) females. Their mean age was $59.3 \pm 12.6$. Twentytwo cases $(55 \%)$ had underlying diseases such as kidney disease, diabetes, hypertension, or heart diseases. The mean length of hospital stay was $10 \pm 6.3$ days. For mechanically ventilated patients, mean days on mechanical ventilation was $5 \pm 3.9$ days. Regarding their inflammatory markers, mean white blood cell count was13.6 \pm 6.8 , mean highest D-dimer level was $3190.8 \pm 4165$, mean highest ferritin level $2436.7 \pm 3287.4$, and mean highest 
CRP $163.3 \pm 121.5$. Twelve patients (30\%) were mechanically ventilated (Table 2 ).

Thirteen patients (32.5\%) died; twenty-seven (67.5\%) improved and discharged. Half of the patients had respiratory coinfections documented by PN panel. All the documented coinfections were of bacterial origin. No viruses or atypical mycobacteria were detected.

Among the 20 coinfected patients, a total of 33 bacteria were identified. The most common isolate was Klebsiella pneumoniae (10/20, 50\%), followed by Acinetobacter calcoaceticus baumanni complex (7/20, 35\%), Enterobacter cloacae complex (5/20, 25\%), and Staphylococcus aureus $(4 / 20,20 \%)$; the four isolates were methicillin resistant as detected by the mecA/C and MREJ genes, Streptococcus agalactia (3/20, 15\%), Haemophilus

Table 2 Demographic data of the studied patients

\begin{tabular}{|c|c|}
\hline $\mathrm{Age}^{\dagger}$ & $59.3 \pm 12.6$ \\
\hline Male to female & $4: 1$ \\
\hline \multicolumn{2}{|l|}{ Main comorbidities } \\
\hline Diabetes & 11 \\
\hline Hypertension & 11 \\
\hline Ischemic heart disease & 9 \\
\hline Renal impairment & 2 \\
\hline Parkinsonism & 1 \\
\hline APACHE II score* & $10(4.5-17)$ \\
\hline \multicolumn{2}{|l|}{ Lab data at ICU admission: } \\
\hline Highest D dimer* (ng/ml) & $1021(610-5346)$ \\
\hline Ferritin* $(\mathrm{ng} / \mathrm{ml})$ & $1366(725-2528)$ \\
\hline $\mathrm{CRP}^{*}(\mathrm{mg} / \mathrm{l})$ & $133.9(54.3-262.3)$ \\
\hline Lymphocytes* (absolute value/ $\mu \mathrm{L}$ ) & $506(326-1052)$ \\
\hline $\mathrm{TLC}^{\dagger}\left(\times 10^{3} / \mu \mathrm{L}\right)$ & $13.6 \pm 6.8$ \\
\hline $\mathrm{ALT}^{*} \mathrm{U} / \mathrm{L}$ & $63.5(37.8-129.8)$ \\
\hline $\mathrm{AST}^{*} \mathrm{U} / \mathrm{L}$ & $66(39-107.5)$ \\
\hline Total Bilirubin*(mg/dl) & $0.6(0.4-0.8)$ \\
\hline Platelets $^{\dagger}\left(\times 10^{3} / \mu \mathrm{L}\right)$ & $342.8 \pm 110.6$ \\
\hline Urea* mg/dl & $66(50-141)$ \\
\hline Creatinine* $\mathrm{mg} / \mathrm{dl}$ & $1.1(0.9-1.3)$ \\
\hline Procalcitonin* ng/dl & $0.1(0.1-0.5)$ \\
\hline \multicolumn{2}{|l|}{ Outcomes in ICU } \\
\hline Mechanical ventilation & $12 / 40$ \\
\hline ICU mortality & $13 / 40$ \\
\hline $\operatorname{LOS}^{\dagger}$ & $10 \pm 6$ \\
\hline \multicolumn{2}{|l|}{ Type of sample } \\
\hline Sputum & 37 \\
\hline BAL & 2 \\
\hline Tracheal aspirate & 1 \\
\hline
\end{tabular}

CRP C-reactive protein, $T L C$ total leukocytic count, LOS length of hospital stay, $B A L$ bronchoalveolar lavage. *Data are represented by median and interquartile range. ${ }^{\dagger}$ Data are represented by mean and standard deviation influenza (1/20, 5\%), Klebsiella aerogenes (1/20, 5\%), Escherichia coli (1/20, 5\%), and Streptococcus pneumoniae $(1 / 20,5 \%)$ (Table 3$)$.

Regarding genetic resistance, thirteen (13/20, 65\%) isolates were proven ESBL-producing Enterobacteriaceae testing positive for CTX. Thirteen (13/20, 65\%) isolates were proven carbapenemase-producing organisms testing positive for NDM, OXA-48, and VIM (7/20, 35\%; 5/ $20,25 \% ; 1 / 20,5 \%$, consequently). The four isolated Staphylococcus aureus were methicillin-resistant testing positive for mecA/C and MREJ (4/20, 20\%) (Table 3).

Considering the laboratory data, AST and TLC were found to be significantly higher in patients with documented respiratory coinfections versus patients without, $\mathrm{p}=0.02$ and 0.05 respectively. On the other hand, the other parameters showed insignificant difference between the two groups (Table 4).

\section{Discussion}

As far as we know, this is the first report focusing on microbiological sampling of respiratory tract samples to detect respiratory coinfections in Covid-19 patients admitted in an ICU in Egypt.

In our study, the most common isolate was Klebsiella pneumoniae (10/20, 50\%), followed by Acinetobacter calcoaceticus baumanni complex (7/20, 35\%). No infection related to atypical bacteria was detected and no viral coinfection.

Numerous reports have been published documenting respiratory coinfections in Covid-19 patients with diverse results.

Verroken et al. had reported (13/32, 40.6\%) of Covid19 patients with documented bacterial coinfection detected by pneumonia panel. Staphylococcus aureus, Haemophilus influenza, and Moraxella catarrhalis were the principal bacteria identified. As similar to our results, none of the FilmArray PN Panel tests identified atypical bacteria neither other respiratory viruses [7].

In a retrospective study in Italy, screening test was done by FilmArray PN panel, bacterial coinfection was detected in 10 of 56 SARS-CoV2-infected patients (17.8\%). Staphylococcus aureus (7/10) was the most common pathogen. Similar to the previous report, no respiratory viruses were identified [8].

Another French study revealed (26/92, 28\%) of Covid19 patients admitted to the ICU were considered as coinfected with a pathogenic bacterium upon ICU admission. The leading involved bacteria were methicillinsensitive Staphylococcus aureus MSSA, Streptococcus pneumoniae, Haemophilus infuenzae, and Enterobacteriaceae. No coinfection with a virus nor atypical bacteria was detected [9].

Pathogens that were prevalent in our samples were obviously different from the abovementioned reports of 
Table 3 Detailed PN panel results of included patients

\begin{tabular}{|c|c|c|c|c|}
\hline Patient no. & Type of sample & FA-PNEU results & Genetic resistance & Outcome \\
\hline 1 & BAL & Klebsiella pneumoniae $\geq 10^{7}$ & CTX-M, NDM, OXA-48 & Death \\
\hline 2 & BAL & - & - & Death \\
\hline 3 & Sputum & Klebsiella pneumoniae $\geq 10^{7}$, Acinetobacter calcoaceticus-baumanni complex $10^{5}$ & CTX-M, NDM, OXA-48 & Death \\
\hline 4 & Tracheal aspirate & Acinetobacter calcoaceticus-baumanni complex $\geq 10^{7}$ & CTX-M, NDM, OXA-48 & Death \\
\hline 5 & Sputum & - & & Death \\
\hline 6 & Sputum & Staphylococcus aureus $10^{6}$, Enterobacter cloacae complex $10^{5}$, Klebsiella pneumoniae $10^{5}$ & CTX-M, OXA-48, mecA/C and MREJ & Discharge \\
\hline 7 & Sputum & Acinetobacter calcoaceticus-baumanni complex $\geq 107$ & NDM & Discharge \\
\hline 8 & Sputum & - & - & Discharge \\
\hline 9 & Sputum & - & - & Discharge \\
\hline 10 & Sputum & - & - & Discharge \\
\hline 11 & Sputum & Klebsiella pneumoniae $\geq 10^{7}$, Escherichia coli $\geq 10^{7}$, & CTX-M & Discharge \\
\hline 12 & Sputum & Acinetobacter calcoaceticus-baumanni complex $\geq 10^{7}$, & NDM & Death \\
\hline 13 & Sputum & - & - & Discharge \\
\hline 14 & Sputum & Streptococcus pneumoniae $10^{6}$, Streptococcus agalactiae $10^{6}$, & CTX-M & Discharge \\
\hline 15 & Sputum & Acinetobacter calcoaceticus-baumanni complex $10^{5}$, & - & Discharge \\
\hline 16 & Sputum & Streptococcus agalactiae $10^{6}$, Enterobacter cloacae complex $10^{5}$, & CTX-M, OXA-48 & Discharge \\
\hline 17 & Sputum & - & - & Discharged \\
\hline 18 & Sputum & - & - & Discharged \\
\hline 19 & Sputum & Staphylococcus aureus $10^{5}$, Klebsiella pneumoniae $10^{5}$, & CTX-M, mecA/C and MREJ & Discharged \\
\hline 20 & Sputum & $\begin{array}{l}\text { Staphylococcus aureus } 10^{5} \text {, Klebsiella pneumoniae } \geq 10^{7} \text {, } \\
\text { Acinetobacter calcoaceticus-baumanni complex } \geq 10^{7} \text {, }\end{array}$ & CTX-M, mecA/C and MREJ & Death \\
\hline 21 & Sputum & - & & Death \\
\hline 22 & Sputum & - & - & Discharge \\
\hline 23 & Sputum & Streptococcus agalactiae $10^{5}$, Klebsiella pneumoniae $\geq 10^{7}$ & CTX-M & Discharge \\
\hline 24 & Sputum & - & - & Discharge \\
\hline 25 & Sputum & Staphylococcus aureus $10^{5}$, Enterobacter cloacae complex $10^{5}$ & mecA/C and MREJ & Discharge \\
\hline 26 & Sputum & Enterobacter cloacae complex $10^{5}$, Klebsiella pneumoniae $10^{5}$ & CTX-M,NDM,VIM & Discharge \\
\hline 27 & Sputum & - & - & Discharge \\
\hline 28 & Sputum & - & - & Death \\
\hline 29 & Sputum & Klebsiella aerogenes $10^{6}$, Klebsiella pneumoniae $10^{5}$ & - & Discharge \\
\hline 30 & Sputum & - & - & Discharge \\
\hline 31 & Sputum & Acinetobacter calcoaceticus-baumanni complex $\geq 10^{7}$ & NDM,OXA-48 & Death \\
\hline 32 & Sputum & & & Discharge \\
\hline 33 & Sputum & - & - & Discharge \\
\hline 34 & Sputum & Enterobacter cloacae complex $10^{6}$ & CTX-M & Death \\
\hline 35 & Sputum & - & - & Discharge \\
\hline 36 & Sputum & haemophilus influenzae $10^{6}$ & - & Discharge \\
\hline 37 & Sputum & - & - & \\
\hline 38 & Sputum & - & - & Discharge \\
\hline 39 & Sputum & - & - & Death \\
\hline 40 & Sputum & Klebsiella pneumoniae $10^{6}$ & СTX-M, OXA-48 & Discharge \\
\hline
\end{tabular}

BAL bronchoalveolar lavage, CTX-M extended spectrum $\beta$-lactamase (ESBL), NDM New Delhi metallo- $\beta$-lactamase, OXA-48 oxacillinase (OXA) $\beta$-lactamases, mecA/C and MREJ methicillin-resistant (MR) staphylococci, VIM Verona Integron-Encoded Metallo- $\beta$-Lactamase

bacterial coinfections in Covid-19 with Klebsiella pneumoniae $(10 / 20,50 \%)$ and Acinetobacter calcoaceticus baumanni complex $(7 / 20,35 \%)$ were the most common pathogens encountered and most of them were ESBLand carbapenemase-producing organisms.
However other reports documented community acquired pathogens such as MSSA, Streptococcus pneumoniae, and Haemophilus infuenzae to be most commonly involved with no mentioned bacterial resistance genetic patterns [7-9]. 
Table 4 Comparison between patients with documented respiratory coinfection versus patients without regarding LOS and laboratory data

\begin{tabular}{|c|c|c|c|}
\hline Variable & Documented respiratory coinfection $(n=20)$ & No documented respiratory coinfection $(n=20)$ & P-value \\
\hline$\overline{\operatorname{LOS}^{+}}$ & $10.05 \pm 6.06$ & $9.95 \pm 6.77$ & $0.961^{\ddagger}$ \\
\hline $\mathrm{TLC}^{\dagger}\left(\times 10^{3} / \mu \mathrm{L}\right)$ & $10.71 \pm 5.14$ & $8.07 \pm 3.26$ & $0.05^{\ddagger}$ \\
\hline Ferritin* $(\mathrm{ng} / \mathrm{ml})$ & $992(266-1730)$ & $595(334-1241)$ & $0.194^{\S}$ \\
\hline $\mathrm{CRP}^{*}(\mathrm{mg} / \mathrm{l})$ & $56.3(15.8-183.9)$ & $54.3(3.8-122.9)$ & $0.33^{\S}$ \\
\hline Lymphocytes* (absolute value/ $\mu \mathrm{L}$ ) & $308(92-486)$ & $337(288-574)$ & $0.337^{\S}$ \\
\hline Highest D-dimer* (ng/ml) & $313(690-4985)$ & $221(458-3487)$ & $0.317^{\S}$ \\
\hline $\mathrm{ALT}^{*}(\mathrm{U} / \mathrm{L})$ & $59(34-184)$ & $68(39-108)$ & $0.73^{\S}$ \\
\hline $\mathrm{AST}^{*} \mathrm{U} / \mathrm{L}$ & $76(43-129)$ & $42(38-72)$ & $0.02^{\S}$ \\
\hline Bilirubin* (mg/dl) & $0.6(0.3-0.9)$ & $0.5(0.4-0.8)$ & $0.98^{\S}$ \\
\hline Platelets ${ }^{\dagger}\left(\times 10^{3} / \mu \mathrm{L}\right)$ & $356.8 \pm 119.27$ & $328.5 \pm 102.38$ & $0.43^{\ddagger}$ \\
\hline Urea* (mg/dl) & $66(51-173)$ & $63(40.5-132.5)$ & $0.41^{\S}$ \\
\hline Creatinine* $(\mathrm{mg} / \mathrm{dl})$ & $1.1(0.8-1.4)$ & $1(0.9-1.2)$ & $0.61^{\S}$ \\
\hline Procalcitonin* (ng/ml) & $0.23(0.07-1.14)$ & $0.05(0.05-0.31)$ & $0.07^{\S}$ \\
\hline
\end{tabular}

LOS length of hospital stay, TLC total leukocytic count, CRP C-reactive protein. *Data are represented by median and interquartile range. ${ }^{\dagger} \mathrm{Data}$ are represented by mean and standard deviation. ${ }^{\ddagger} \mathrm{T}$ test. ${ }^{\S} \mathrm{Mann}-$ Whitney test

The different patterns of prevalent bacteria have several explanations.

First, the samples were not all collected during the first hours of admission that could show initial disease presentation. As it was reported in previous reports that most of the patients with SARS-CoV-2 pneumonia have no respiratory secretions with only $25-30 \%$ of them having sputum production [10] so not all patients were able to collect their sputum samples in the first $24 \mathrm{~h}$ and the samples were collected as soon as the patient was able to expectorate his sputum. Therefore, most of the isolated bacteria was after $48 \mathrm{~h}$ of admission so it reflects the hospital acquired pathogens.

Second, this difference in isolated bacteria is obviously attributed to the different local microbiome. A multicenter study conducted in 3 major tertiary care Egyptian hospitals analyzed the results of lower respiratory tract samples of hospitalized patients with hospital acquired pneumonia, Klebsiella pneumoniae was the commonest isolated gram-negative pathogen (91/128, 71.1\%) followed by Escherichia coli (34/128, 26.6\%) [4]. Another large multicenter study was done in 91 ICUs in Egyptian hospitals. There were 2688 ICU-onset infections reported during the surveillance period. The most common pathogens reported were Klebsiella pneumoniae (28.7\%) and Acinetobacter (13.7\%) [11].

Several causes are attributed to the high prevalence of MDR gram-negative pathogens. Limitation in implementing stewardship programs and strict infection control measures in the hospitals as well as over prescription of antibiotics, being available over the counter in outpatient settings. All of this had led to the widespread prevalence of MDR pathogens in Egyptian hospitals. Consequently, the clinicians especially the intensivist are continuously faced with challenging clinical situations.

Although there was high prevalence of bacterial coinfection in our cohort, however none of the samples tested positive for atypical bacteria, which is in line with other reports [7-9]. This question the systematic use of antimicrobials targeting atypical bacteria in these patients. This is particularly relevant since some of these drugs have been associated with acute cardiotoxicity (QT interval prolongation when co-administered with other drugs such as hydroxychloroquine) [12].

No viral coinfection was detected in our cohort of critically ill Covid-19 patients, especially no influenza viruses. This was in agreement with the previous mentioned reports [7-9]. This finding discourages the systematic prescription of an empirical antiviral treatment with neuraminidase inhibitors in critically ill patients with a confirmed SARSCoV-2 pneumonia.

Further studies on large number of patients in multicenters are needed to be carried out to detect the true prevalence of respiratory coinfections in COVID patients. Additionally, similar studies are required to be carried out selectively on outpatient settings. This will facilitate implementation of precise management strategies and detection of the most appropriate antibiotics, if any should be used, to be prescribed on outpatient settings.

Finally concomitant samples should be sent to be tested by routine conventional cultures to be compared with BioFire results in order to clearly identify specificity and sensitivity of BioFire Pneumonia Panel test. 


\section{Conclusion}

In our cohort of studied patients, we have found 50\% rate of bacterial respiratory coinfection in patients with severe SARS COV-2 admitted in the ICU. The most common detected pathogens were Klebsiella pneumoniae $(10 / 20,50 \%)$ and Acinetobacter calcoaceticus baumanni complex $(7 / 20,35 \%)$ that are resistant to the extended-spectrum antibiotics. Hence, secondary bacterial coinfection is an undeniable fact in patients with SASRS-COV-2. Systemic administration of broadspectrum antibiotics especially antibiotics covering ESBLs being the most prevalent pathogens is recommended with prompt de-escalation as soon as possible.

\begin{abstract}
Abbreviations
COVID-19: Coronavirus disease 2019; PCR: Polymerase chain reaction; PN panel: Pneumonia panel; ESBL: Extended spectrum beta lactamase; CTX: Extended spectrum $\beta$-lactamase (ESBL); NDM: New Delhi metallo- $\beta$ lactamase; OXA-48: Oxacillinase $\beta$-lactamases; VIM: Verona Integron-Encoded Metallo- $\beta$-Lactamase; ICU: Intensive care unit; SARS-COV-2: Severe acute respiratory syndrome coronavirus 2; CRP: C reactive protein; MDR: Multi-drugresistant; ETA: Endotracheal tube aspirate; RT-PCR: Reverse transcriptase polymerase chain reaction; QSM: Quantified standard material; ICU: Intensive care unit; MRSA: Methicillin-resistant Staphylococcus aureus; mecA/C and MREJ: Methicillin-resistant (MR) staphylococci; MSSA: Methicillin-sensitive Staphylococcus aureus
\end{abstract}

\section{Acknowledgements}

We thank Dr Mohamad Sadek (Director of Infection Control Department) for his continuous support and help. We thank ICU residents for recruiting the patients. We thank nursing staff, lab doctors, and technicians for being helpful and cooperative.

\section{Declarations}

\section{Authors' contributions}

Conceptualization: $\mathrm{AH}, \mathrm{SM}$; methodology: $\mathrm{AH}$; formal analysis: $\mathrm{AH}, \mathrm{KR}$; data curation: IA; software: $E A$; validation: $A M$; investigation: $M H, A M$; writing-original draft preparation: $\mathrm{AH}, \mathrm{AM}, \mathrm{EA}$; writing-review and editing: $\mathrm{AH}, \mathrm{SM}, \mathrm{IA}, \mathrm{KR}, \mathrm{MH}, \mathrm{AM}$; approval of final manuscript: all authors

\section{Funding}

No fund was paid by any organization.

\section{Availability of data and materials}

Data are available.

\section{Ethics approval and consent to participate}

The study protocol was approved by the institutional review board of Ministry of Health, Cairo, Egypt (No: 3-2021/19).

\section{Consent for publication}

Not applicable

\section{Competing interests}

The authors declare that they have no competing interests.

\section{Author details}

'Department of Chest Medicine, Faculty of Medicine, Cairo University, Al Kasr Al Aini, Old Cairo, Cairo 11956, Egypt. ${ }^{2}$ Department of Anaethesia, Faculty of Medicine, Cairo University, Cairo, Egypt. ${ }^{3}$ Laboratory Department, Misr International Hospital, Cairo, Egypt. ${ }^{4}$ Infectious Diseases Consultants and Academic Researchers of Egypt (IDCARE), Cairo, Egypt. ${ }^{5}$ Internal Medicine department, Faculty of Medicine, Cairo University, Cairo, Egypt. ${ }^{6}$ Intensive Care Department, Faculty of Medicine, Ain Shams University, Cairo, Egypt.
Received: 6 May 2021 Accepted: 3 June 2021

Published online: 24 June 2021

\section{References}

1. World Health Organization. Coronavirus disease (COVID-2019) situation reports. 2020. Available at: https://www.who.int/emergencies/diseases/ novel-coronavirus-2019/situation-reports/. Accessed November 25, 2020.

2. Wan S, Xiang Y, Fang W, Zheng Y, Li B, Hu Y et al (2020) Clinical Features and Treatment of COVID-19 Patients in Northeast Chongqing. J Med Virol 21

3. Yang X, Yu Y, Xu J, Shu H, Xia J, Liu H et al (2020) Clinical course and outcomes of critically ill patients with SARS-CoV-2 pneumonia in Wuhan, China: a single-centered, retrospective, observational study. Lancet Respir Med 8(5):475-481. https://doi.org/10.1016/S2213-2600(20)30079-5

4. Kotb S, Lyman M, Ismail G, Abd El Fattah M, Girgis S, Etman A et al (2020) Epidemiology of Carbapenem-resistant Enterobacteriaceae in Egyptian intensive care units using National Healthcare- associated Infections Surveillance Data, 2011-2017. Antimicrob Resist Infect Control 9:2

5. Yoo IY, Huh K, Shim HJ, Yun SA, Yoo Na Chung YN et al (2020) Evaluation of the BioFire FilmArray Pneumonia Panel for rapid detection of respiratory bacterial pathogens and antibiotic resistance genes in sputum and endotracheal aspirate specimens. Int J Infect Dis 95:326-321

6. Buchan B, Windham S, Balada-Llasat J, Leber A, Harrington A, Ryan Relich R et al (2020) Practical comparison of the BioFire FilmArray Pneumonia panel to routine diagnostic methods and potential impact on antimicrobial stewardship in adult hospitalized patients with lower respiratory tract infections. J Clin Microbiol 58(7)

7. Verroken A, Scohy A, Gerard L, Wittebole X, Collienne C, Laterre P (2020) Coinfections in COVID-19 critically ill and antibiotic management: a prospective cohort analysis. Crit Care 24(1):410. https://doi.org/10.1186/s13 054-020-03135-7

8. Calcagno A, Ghisetti V, Burdino E, Trunfio M, Allice T, Boglione L, Bonora S, Di Perri G (2020 (articles in press) Coinfection with other respiratory pathogens in COVID-19 patients. Clin Microbiol Infect. https://doi.org/10.101 6/j.cmi.2020.08.012

9. Contou D, Claudinon C, Pajot O, Micaëlo M, Flandre PL, Dubert M (2020) Bacterial and viral co-infections in patients with severe SARS-CoV-2 pneumonia admitted to a French ICU. Ann Intensive Care 10(1):119. https:// doi.org/10.1186/s13613-020-00736-x

10. Guan W-J, Ni Z-Y, Hu Y, Liang W-H, Ou C-Q, He J-X, Liu L, Shan H, Lei CL, Hui DSC, du B, Li L, Zeng G, Yuen KY, Chen RC, Tang CL, Wang T, Chen PY, Xiang J, Li SY, Wang JL, Liang ZJ, Peng YX, Wei L, Liu Y, Hu YH, Peng P, Wang JM, Liu JY, Chen Z, Li G, Zheng ZJ, Qiu SQ, Luo J, Ye CJ, Zhu SY, Zhong NS, China Medical Treatment Expert Group for Covid-19 (2020) Clinical characteristics of coronavirus disease 2019 in China. N Engl J Med 382(18):1708-1720. https://doi.org/10.1056/NEJMoa2002032

11. Talaat M, El-Shokry M, El-Kholy J, Ismail G, Kotb S, Hafez S et al (2016) National surveillance of health care-associated infections in Egypt: developing a sustainable program in a resource-limited country. Am J Infect Control 44(11):1296-1301. https://doi.org/10.1016/j.ajic.2016.04.212

12. Guo D, Cai Y, Chai D, Liang B, Bai N, Wang R (2010 Sep) The cardiotoxicity of macrolides: a systematic review. Pharmazie 65(9):631-640

\section{Publisher's Note}

Springer Nature remains neutral with regard to jurisdictional claims in published maps and institutional affiliations. 